\title{
Surgery for greater trochanteric pain syndrome after total hip replacement confers a poor outcome
}

\author{
Eve Robertson-Waters $^{1,2}$ (1) James R. Berstock ${ }^{1,2}$ - Michael R. Whitehouse ${ }^{1,2}$ • $^{-}$ \\ Ashley W. Blom ${ }^{1,2}$
}

Received: 26 January 2017 / Accepted: 14 June 2017 / Published online: 28 July 2017

(C) The Author(s) 2017. This article is an open access publication

\begin{abstract}
Purpose Surgery for greater trochanteric pain syndrome (GTPS) may be indicated for cases refractory to conservative measures. We aim to evaluate patient reported outcomes and adverse events following surgery.

Methods Postal questionnaires were used to evaluate a consecutive series of 61 bursectomy and gluteal fascia transposition (GFT) procedures. Study outcomes were Oxford hip score, satisfaction score, visual analogue score, pain lying on the affected side, and the duration of pain relief after surgery. Results We received responses regarding 52 procedures at a median of 34 months follow-up; $40 \%$ of cases of GTPS occurred following THA. We observed a bimodal distribution of satisfaction scores. The early post-operative complication rate was $13 \%$; an additional seven cases $(12 \%)$ required further surgery at a later date. Idiopathic GTPS had significantly better post-operative satisfaction than GTPS following THA, 87.5
\end{abstract}

Eve Robertson-Waters

er12834@my.bristol.ac.uk

James R. Berstock

James.Berstock@bristol.ac.uk

Michael R. Whitehouse

Michael.Whitehouse@bristol.ac.uk

Ashley W. Blom

Ashley.Blom@bristol.ac.uk

1 Musculoskeletal Research Unit, School of Clinical Sciences, University of Bristol, Level 1 Learning and Research Building, Southmead Hospital, Westbury-on-Trym, Bristol BS10 5NB, UK

2 Department of Orthopaedics, Brunel Building, Southmead Hospital, Southmead Road, Westbury-on-Trym, Bristol, Avon BS10 5NB, UK vs. $37.5(p=0.006)$; Oxford hip scores, 35 vs. $15(p=0.015)$; and visual analogue scores, 20 vs. $73(p=0.005)$.

Conclusion We observed overall poor outcomes, significant complications and concerning reoperation rates. Cases with previous joint replacement were associated with the worst outcomes.

Keywords Hip · Pain · Bursitis

\section{Introduction}

Greater trochanteric pain syndrome (GTPS) is a clinical diagnosis of disabling pain localised over the lateral aspect of the hip [1,2] worsened by lying on the affected side. What was once thought of, and is still sometimes referred to, as 'trochanteric bursitis' is now understood to involve a wider number of structures surrounding the greater trochanter including tendinopathy and micro-trauma to the gluteus medius and minimus tendons [3] (Fig. 1), often without classic signs of inflammation implied by the term 'bursitis' [4].

The prevalence of GTPS in the general population ranges from 10 to $25 \%$ [5]. When participants of an observational study aged between 50 and 79 years were specifically questioned and examined for features of GTPS, the prevalence was identified at $17.6 \%$ [4].

A recent series of patients undergoing a trochanteric bursa injection for GTPS rated the pain 6.1 out of 10 in severity on a verbal numeric pain scale, and reported poor function (mean 50.1) on Harris hip scoring prior to the injection [6].

Following total hip arthroplasty (THA) $4-17 \%$ of patients report symptoms of GTPS [7-10]. Low back pain, hip osteoarthritis [11] and rheumatoid arthritis [12], also appear to be predisposing factors. Furthermore, there appears to be a 


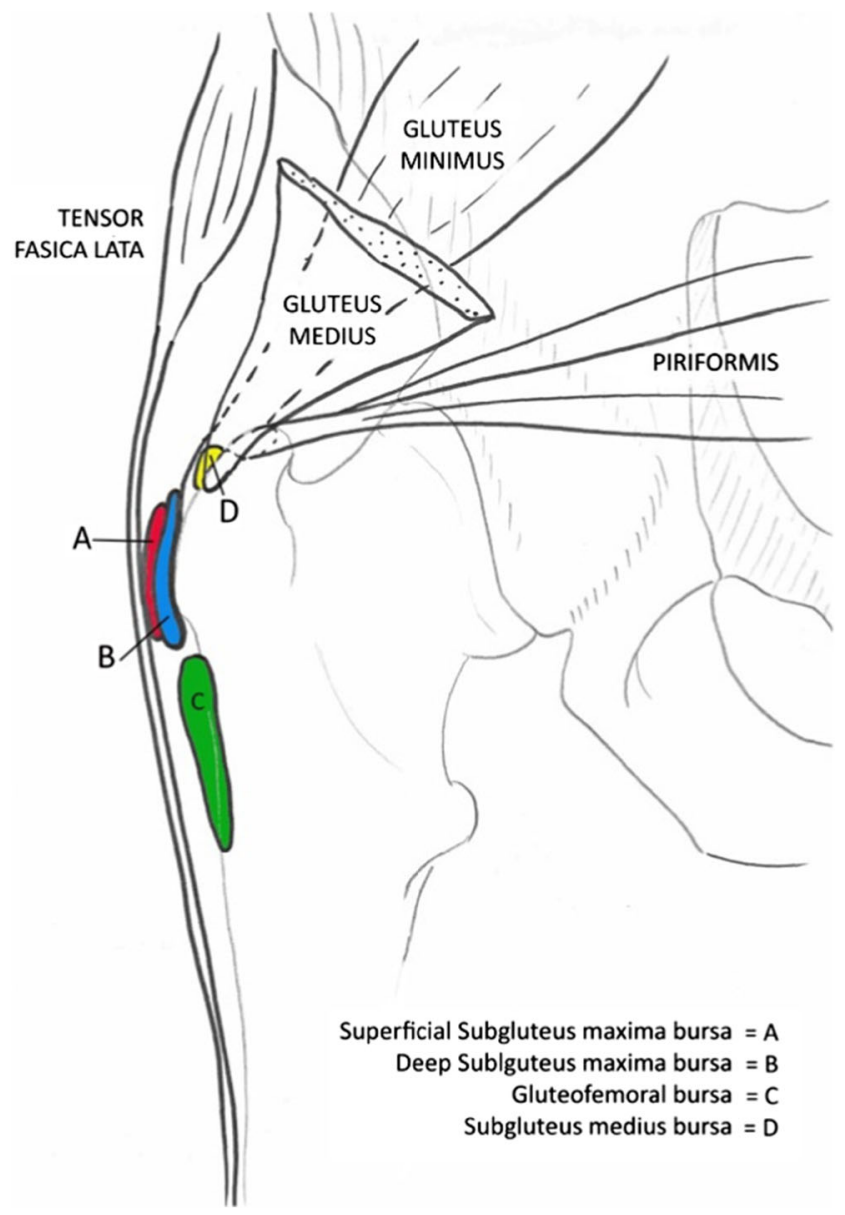

Fig. 1 Posterior aspect of the anatomy around the greater trochanter, showing structures commonly implicated in greater trochanteric pain syndrome

female preponderance, suggesting hip biomechanics including femoral offset may also play a role [4].

Most cases are managed conservatively with simple analgesia, physiotherapy and corticosteroid injections. For refractory cases of GTPS where conservative measures have failed, numerous surgical techniques have been described [13].

Gluteal fascia transposition (GFT) has been described previously as a technique to decompress the greater trochanteric region [14]. To summarise, an 'H-shaped' incision is made in the fascia lata over the greater trochanter and the resulting flaps are folded back on themselves and secured with sutures. This technique is also known as fascial windowing. The underlying bursa is then excised.

Many studies looking at the efficacy of surgical techniques for GTPS exclude patients who have undergone previous THA $[15,13]$. However, these patients may make up a significant proportion of refractory cases:
Baker et al. [14] report preliminary data to suggest that the aetiology of GTPS may have an effect on outcome following GFT, with idiopathic cases appearing to have a more satisfactory outcome than those with previous THA or revision.

This study aims to retrospectively evaluate patient reported outcomes and adverse events following trochanteric bursectomy and gluteal fascia transposition, in relation to aetiology, in a consecutive case series of patients treated by multiple surgeons at our institution.

\section{Patients and methods}

Institutional approval was obtained for this study. The BlueSpier (Bluespier, Droitwich, Worcester, UK) electronic database of clinical records was used to retrospectively identify all patients who underwent bursectomy and GFT at our institution between January 2010 and October 2015. Of the 62 procedures we identified in 59 patients, we excluded one patient who presented with a chronic infective bursitis following corticosteroid injection. All included patients had a clinical diagnosis of GTPS (defined by pain around the greater trochanter), had failed conservative treatment (defined as the return of symptoms following at least one successful corticosteroid injection, physiotherapy or both), and had been symptomatic for over one year at the time of surgery.

The clinical records of patients were reviewed and the following data recorded: age; gender; duration of symptoms; underlying aetiology (idiopathic, ipsilateral THA, bilateral THA, ipsilateral total knee arthroplasty, traumatic, rheumatoid arthritis); presence of low back pain or ipsilateral hip osteoarthritis; previous surgery for GTPS; complications; any further procedures carried out since the index GFT.

We sent postal questionnaires to 58 eligible patients regarding 61 fascial transpositions (three patients experienced bilateral GTPS) at a median of 34 months postoperatively (range 9-77). In the absence of a specific validated outcome tool, the following patient reported outcome measures were included: patient satisfaction score; $10 \mathrm{~cm}$ visual analogue score referring to current level of pain (0-100, 0 representing no pain); Oxford hip score [16] (OHS; with a score of 0 representing worst function, and 48 best function); Likert scale duration of pain relief following the operation; Binary presence of pain when lying on affected side. 
Table 1 Demographics of study population by aetiology

\begin{tabular}{lllrc}
\hline Aetiology & $\begin{array}{l}\text { Number of fascial } \\
\text { window procedures }\end{array}$ & $\begin{array}{l}\text { Median age } \\
\text { (interquartile } \\
\text { range) }\end{array}$ & Males & Females \\
\hline $\begin{array}{l}\text { Idiopathic } \\
\text { Bilateral }\end{array}$ & 31 & $58(50.5-67)$ & 7 & 24 \\
$\quad$ THA & 8 & $72(65-74)$ & 3 & 5 \\
$\begin{array}{l}\text { Ipsilateral } \\
\text { THA }\end{array}$ & 10 & $69(57-74)$ & 2 & 8 \\
$\begin{array}{l}\text { Revision } \\
\text { THA }\end{array}$ & 7 & $77(76-81)$ & 2 & 5 \\
$\begin{array}{l}\text { THA (all) } \\
\text { Rheumatoid }\end{array}$ & 25 & $74(65-77)$ & 7 & 18 \\
$\quad$ arthritis & 1 & 64 & 0 & 2 \\
$\begin{array}{l}\text { Traumatic } \\
\text { Unavailable }\end{array}$ & 2 & 62 & 0 & 1 \\
$\begin{array}{l}\text { Total } \\
\text { nol }\end{array}$ & 61 & 65 & 0 & 2 \\
\hline
\end{tabular}

Satisfaction was measured according to the method described by Mahomed [17]. This scale consists of four items focusing on satisfaction with the extent of pain relief, improvement in ability to perform home activities, recreational activities and overall satisfaction. The responses were scored on a stemmed Likert scale (Appendix 1), with the scale score being the mean of the four parts and ranging from 25 (least satisfied) to 100 (most satisfied).

Missing data were completed where possible via telephone interview by one of the authors (ERW). The mean value substitution method was used when a maximum of one data point was not reported for an outcome measure. IBM SPSS Statistics for Windows, v22.0 (IBM Corp; Armonk, NY) was used for statistical analysis. A Mann-Whitney $U$ test was used to compare the outcome of surgical intervention between cases with an idiopathic aetiology and those who had undergone previous THA. Pearson coefficients were used to determine if there was a correlation between the reported outcome scores.

\section{Results}

We received responses from 49 patients, regarding $52(85 \%)$ bursectomy and gluteal fascia transposition procedures. Demographic data for the study population are presented according to aetiology in Table 1. Age differed significantly between the idiopathic group (median age 58) and THA group (median age 74), $p<0.05$. The results of pre-operative pelvic radiographs and ultrasound scans (USS) are summarised in Table 2. Plain AP radiographs were available for review in 44 out of 49 patients. The most prevalent abnormality was the presence of a bony spur over the trochanter. No varus hips (neck-shaft angle $<120^{\circ}$ ) were identified however there were two valgus hips in the idiopathic GTPS group (neck-shaft angle $>140^{\circ}$ ). An additional preoperative USS was performed for 38 patients, revealing signs of either trochanteric bursitis or gluteal tendinopathy in 36 cases, see Table 2. Responders and non-responders were not significantly different in median age, length of follow-up or female preponderance. However, one patient in the THA group did

Table 2 Hip ultrasound (USS) and radiographical features by aetiology

\begin{tabular}{|c|c|c|c|c|c|c|c|c|c|c|}
\hline Aetiology & Total & $\begin{array}{l}\text { Hip } \\
\text { radiographs } \\
\text { available }\end{array}$ & $\begin{array}{l}\text { Bony } \\
\text { Spur }\end{array}$ & $\begin{array}{l}\text { Reduced } \\
\text { off-set }\end{array}$ & $\begin{array}{l}\text { Increased } \\
\text { off-set }\end{array}$ & $\begin{array}{l}\text { USS } \\
\text { available }\end{array}$ & $\begin{array}{l}\text { USS diagnosis of } \\
\text { bursitis } \\
\text { (trochanteric/ } \\
\text { gluteal) alone }\end{array}$ & $\begin{array}{l}\text { USS } \\
\text { diagnosis of } \\
\text { tendinopathy } \\
\text { alone }\end{array}$ & $\begin{array}{l}\text { USS diagnosis of } \\
\text { mixed } \\
\text { tendinopathy and } \\
\text { bursitis }\end{array}$ & $\begin{array}{l}\text { No evidence } \\
\text { of pathology } \\
\text { on USS }\end{array}$ \\
\hline Idiopathic & 31 & 27 & 14 & 0 & 0 & 18 & 12 & 3 & 1 & 2 \\
\hline $\begin{array}{c}\text { Bilateral } \\
\text { THA }\end{array}$ & 8 & 8 & 6 & 0 & 3 & 7 & 5 & 0 & 2 & 0 \\
\hline $\begin{array}{c}\text { Ipsilateral } \\
\text { THA }\end{array}$ & 10 & 10 & 7 & 0 & 0 & 7 & 5 & 0 & 2 & 0 \\
\hline $\begin{array}{l}\text { Revision } \\
\text { THA }\end{array}$ & 7 & 6 & 1 & 2 & 0 & 5 & 3 & 0 & 2 & 0 \\
\hline $\begin{array}{c}\text { Rheumatoid } \\
\text { arthritis }\end{array}$ & 2 & 2 & 0 & 0 & 0 & 2 & 2 & 0 & 0 & 0 \\
\hline Traumatic & 1 & 1 & 0 & 0 & 0 & 0 & - & - & - & - \\
\hline Unavailable & 2 & 2 & 1 & 0 & 0 & 1 & 0 & 0 & 1 & 0 \\
\hline
\end{tabular}

40 of 61 cases underwent USS preoperatively. In a number of cases, tendinopathy and trochanteric bursitis were diagnosed together; 56 of 61 cases underwent hip x-ray preoperatively. One traumatic case occurred after fractured neck of femur, fixed with cannulated screws. THA = total hip arthroplasty 

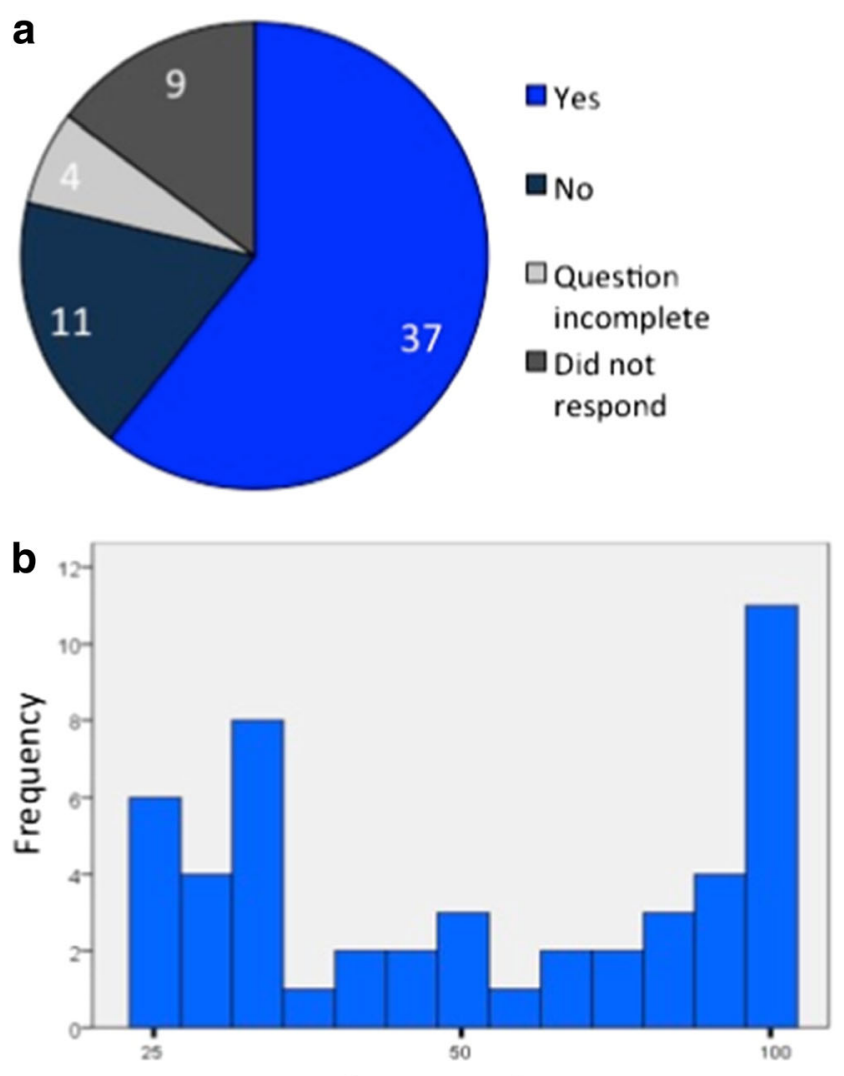

Satisfaction Scale Score

Fig. 2 a Answers of all 61 patients to the question 'Do you get pain lying on the affected side?' at a median of 34 months following gluteal fascial transposition and bursectomy. Question incomplete = no answer given; Did not respond $=$ patients who did not return the questionnaire. $\mathbf{b}$ Frequency of satisfaction scale scores amongst 52 patients who responded. The lowest score is 25 and the highest score is 100 , signifying the most satisfaction

not respond, compared to six in the idiopathic group. Both cases where the aetiology was unknown did not respond.

Prior surgery for GTPS had been undertaken in six patients in the ipsilateral hip: two labral tear repairs; two fascial windowing; one Z-lengthening; one arthroscopic psoas repair. An additional procedure at the same time as bursectomy and GFT occurred in seven patients: two bony debridement of lateral flare; two abductor reattachment; one psoas release; one repair of short external rotators; one osteophyte removal.

\section{Outcomes}

At a median of 34 months follow up, median visual analogue score (VAS) of 52 responses was 53 (interquartile range 1075). Only four patients reported being completely pain free

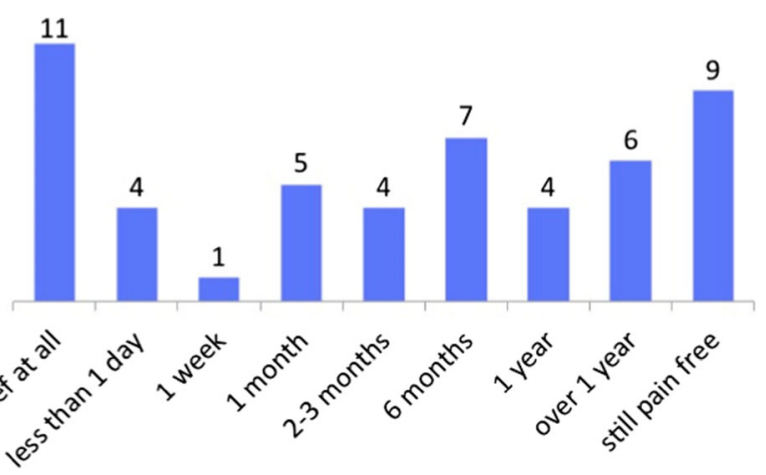

Fig. 3 Length of pain relief following operation, for 51 patients who responded to the question, 'Following your operation, for how long did you have pain relief before your symptoms returned?'

(VAS pain of 0 ). The median OHS was 25 (interquartile range 12-40).

\section{Pain lying on side}

Figure $2 \mathrm{~A}$ shows the responses of the total patient group to the question, 'Do you get pain lying on the affected hip?'. Of the 48 responses completed, 37 (77\%) continued to have pain lying on their side following GFT.

\section{Satisfaction}

The results of the 52 responses to our satisfaction survey are displayed in Fig. 2b. The distribution of scores was bimodal and symmetrical with a median satisfaction scale score of 62.5 (interquartile range 37.5-93.75) and modes at 100 and 37.5.

\section{Pain relief}

Figure 3 shows patient responses to the question 'Following your operation, for how long did you have pain relief before your symptoms returned?'. Of 51 responses, 11 report no relief at all; in comparison, nine were still pain free at follow-up. Nineteen cases were pain free for a year or more.

\section{Complications}

Complications arose after eight of 61 operations in seven patients as follows: three significant post-operative bleeding; one haematoma; two wound infections; one persistent wound infection requiring multiple debridement operations and prosthetic joint infection; one required revision of GFT and LARS ligament (Corin, Cirencester, UK) augmented tendon repair due to persistent pain. A further seven hips 
Fig. 4 Satisfaction scale scores, visual analogue scoring (VAS) and Oxford hip scoring (OHS) analysed by aetiology of greater trochanteric pain syndrome (GTPS). Medians are shown (bars), with boxes showing interquartile range and whiskers showing range. $p<0.05$ was deemed a significant difference in median scores on Mann Whitney U testing

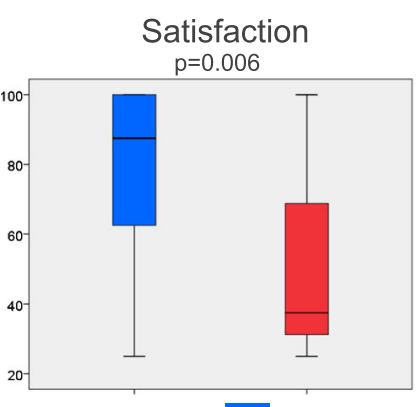

Idiopathic, $\mathrm{n}=25$
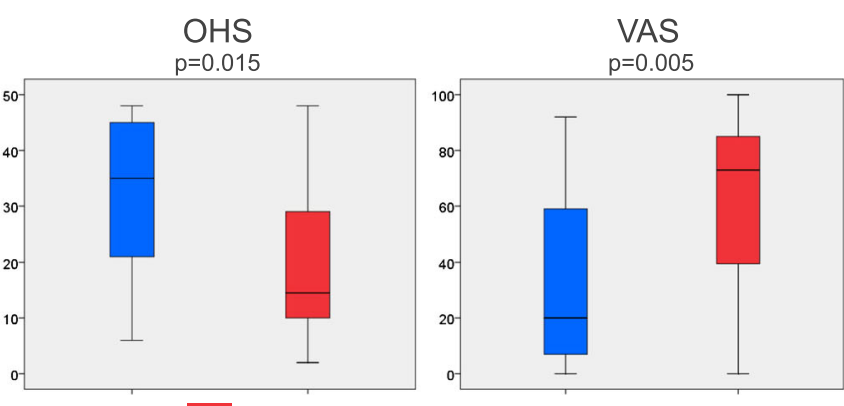

Previous total hip arthroplasty, $n=25$ required additional operations for GTPS following the index fascial transposition: two LARS ligament augmented gluteal tendon repairs, two revision THA, two psoas releases, one excision of bony spur.

\section{Outcome by aetiology}

Postoperative VAS, OHS and satisfaction scores were compared for those with idiopathic aetiology and those with GTPS following THA (Fig. 4). Median satisfaction scores were 37.5 following THA vs. 87.5 for idiopathic cases $(p=0.006)$; median VAS were 73 THA vs. 20, idiopathic $(p=0.005)$; median OHS were 15 THA vs. 35 idiopathic $(p=0.015)$.

Although idiopathic cases tended to be younger, satisfaction scores, VAS and OHS of respondents were not associated with age, gender, the presence or absence of low back pain or osteoarthritis in the same hip using regression analysis. It is not possible to know whether previous surgery was associated with significantly worse outcome measures due to the small sample size.

\section{Reliability of outcome measures}

There was significant correlation between satisfaction scoring, VAS and OHS ( $p<0.001$ for all cases). There was positive correlation between satisfaction and OHS $(r=0.62)$, and a negative correlation between OHS and VAS $(r=-0.902)$, and satisfaction and VAS $(r=-0.701)$. All patients who answered that they were still pain free had VAS scores of 20 or lower, suggesting reliability of the different outcome measures used.

\section{Discussion}

We report a wide variation in outcomes following bursectomy and GFT, suggesting that this surgical intervention does not consistently produce a reliable outcome for refractory cases of
GTPS. A disappointingly large number of patients in our case series were dissatisfied with the results of surgery, which is compounded by the relatively low overall median Oxford hip score of 25 ( 0 worst, 48 best) revealing the disabling nature of this condition, despite a course of conservative therapy and surgical intervention.

Numerous alternative surgical procedures attempt to treat patients with GTPS including open and arthroscopic bursectomy, iliotibial band Z-lengthening, open or arthroscopic tendon repair, and trochanteric osteotomy [13]. In contrast to some other surgical methods, GFT aims to decompress the greater trochanter with excision of the bursa tissue. Whether the fascia is a key contributing cause in the pathoaetiology of GTPS is however unknown.

To our knowledge there has only been one previous study reporting outcomes of bursectomy and GFT [14]. In comparison with this previous study, our results are disappointing. Approximately half of patients in our study were satisfied with their outcome, compared with $75 \%$ in the previous study. Our results show that postoperative satisfaction, pain scores and OHS were significantly worse in cases with previous THA compared to idiopathic cases. With these patients making up $40 \%$ of cases in our series, our data add to those presented by Baker et al. [14], and are of significance because a consistent and major exclusion factor in studies of outcome following surgery for GTPS is previous ipsilateral THA [13, 15].

We hypothesised that the difference in outcome between idiopathic cases and those following THA may be related to differences in the underlying pathology or age; however, we were not able to identify pathological differences on the basis of ultrasound scanning. Similarly, although idiopathic cases were significantly younger, age did not correlate to any measure of outcome, suggesting that advancing age did not account for the poor outcomes of fascial release after THA. In our series, only five of 25 cases had altered femoral offset following THA, suggesting cases following THA do not necessarily occur due to altered hip biomechanics. Future 
research might uncover differences in the pathology of THA and idiopathic cases of GTPS. In the meantime, we suggest that patients with GTPS following THA should be appropriately counselled about the poor outcome of gluteal fascial release and bursectomy.

Early complications in both studies were reported in $13 \%$ of patients. Although most complications in our series were easily treated such as post-operative bleeding, haematoma and superficial infection, we report one devastating prosthetic joint infection. In addition, a notable proportion of patients require further surgery for GTPS suggesting their pain was not improved; a finding not previously reported for this operation. Complications reported in other surgical techniques for GTPS appear to be similar in nature [13] but have varying rates. Similarly, other studies report substantial rates of re-operation $[13,18]$.

Alternative surgical management, notably gluteal tendon repair, has been associated with better outcomes $[19,20]$. In 72 patients with GTPS undergoing gluteal tendon repair, $90 \%$ had no or minimal pain maintained at six and 12 months [20]. In these reports, a specific diagnosis of gluteal tendinopathy was identified on MRI, suggesting that surgery targeted at a specific pathology may be more effective. However, arthroscopic bursectomy without fascial release also appears to have encouraging outcomes at mid-term follow-up [18, 21] with low VAS scores at two years post-operatively, in patients with clinical features of GTPS.

Interpreting the current literature is complicated by the range of underlying pathology which is not always described, the difference in natural history between de novo and recalcitrant GTPS, the lack of specific diagnostic criteria and a lack of a specific tool to measure outcomes in GTPS; as such, widely varying outcomes are reported. However, common to many reports is the exclusion of cases with previous THA. The overall poorer outcomes in our study of GFT for GTPS compared to studies of other surgical techniques may be explained by this difference.

A recent systematic review revealed a lack of evidence to inform the management of GTPS [13]. For conservative measures, four randomised controlled trials have revealed modest but temporary symptomatic relief following corticosteroid injections, and shockwave therapy. The evidence base for patients with recalcitrant GTPS who have not responded to the usual conservative measures is limited to small case series, with variable success reported [13]. We propose that any more invasive surgical treatment method should be superior in not only effect but also length of symptomatic relief. In our case series, at median follow-up of 34 months, $41 \%$ retrospectively reported being pain-free for one year, but only four patients were pain free (VAS of 0 ) at time of follow-up. To our knowledge no prospective studies have directly compared surgical treatments with conservative measures. Such a trial is required, especially in the setting of refractory GTPS where it is important to know if surgery is superior to the continuation of nonoperative measures.

Our retrospective case series is limited by a lack of baseline patient reported outcome measures. However, it has a relatively large sample size compared to other case series of surgical interventions for GTPS [14]. We were unable to identify whether physiotherapy was used as an adjunct to surgery in the cases in this series. The complications we report are important to note if surgical intervention is being considered for this condition. This study also importantly reports outcomes beyond the usual clinical follow up period for this patient group, and beyond that reported in other studies.

\section{Conclusion}

We report overall poor outcomes following GFT and bursectomy for patients with refractory GTPS. The significant complications and rates of further surgery are concerning and are comparable to those reported in studies of other surgical methods for GTPS. We note significantly worse outcomes in those who have undergone previous THA, compared to idiopathic cases. Patients with previous THA are an important group of patients, who commonly undergo surgical treatment for refractory GTPS but are excluded from other studies. Where cases of GTPS remain refractory to treatment with standard conservative measures such as corticosteroid injection (which tend to produce only temporary symptomatic relief) we note the urgent need for a trial comparing specialist conservative management with targeted surgery in terms of length and degree of efficacy.

\section{Compliance with ethical standards}

Conflicts of interest Eve Robertson-Waters, James Berstock, Michael Whitehouse and Ashley Blom declare no conflict of interest.

Funding This research did not receive any specific grant from funding agencies in the public, commercial, or not-for-profit sectors. 
Appendix 1. Patient Questionnaire and Satisfaction Questions

\begin{tabular}{|c|}
$\substack{\text { North Bristol W/S } \\
\text { NHS Trust }}$ \\
\hline
\end{tabular}

\section{Post-Operative Questionnaire}

\section{Name: $\mathbf{X X X X X X X X X}$ \\ Date of Birth: $\mathbf{X X} / \mathbf{X X} / \mathbf{X X}$ \\ Patient ID: 1 \\ Surgery: Right Hip Fascial Windowing}

Our records indicate that you had a Right hip fascial windowing on 30/09/2014 at Southmead Hospital. You had this operation because you were experiencing pain over the side of your Right hip. This is known as 'greater trochanteric pain syndrome'.

We would like to ask you some questions about your satisfaction with the results of the procedure. Please answer in relation to your Right hip only.

Please be aware that any responses will remain anonymous and confidential and will not affect your treatment in any way. You are under no obligation to answer any or all of the questions if you do not wish to do so.

If you have had any other surgery on your Right hip since the fascial windowing 20 months ago, please let us know here:

question. Please return this questionnaire in the freepost envelope provided, thank you.

\section{Part 1: Satisfaction}

1. How satisfied are you with the results of your Right hip fascial windowing ....

\begin{tabular}{|l|l|l|l|l|}
\cline { 2 - 5 } & $\begin{array}{c}\text { Very } \\
\text { satisfied }\end{array}$ & $\begin{array}{c}\text { Somewhat } \\
\text { satisfied }^{2}\end{array}$ & $\begin{array}{c}\text { Somewhat } \\
\text { dissatisfied }^{3}\end{array}$ & $\begin{array}{c}\text { Very } \\
\text { dissatisfied }^{4}\end{array}$ \\
\hline \hline $\begin{array}{l}\text { i) for relieving your pain? } \\
\text { ii) for improving your ability to do } \\
\text { household tasks or gardening } \\
\text { (such as cooking, cleaning, } \\
\text { gardening work)? }\end{array}$ & & & \\
\hline $\begin{array}{l}\text { iii) for improving your ability to do } \\
\text { recreational activities (such as } \\
\text { walking, swimming, playing } \\
\text { golf, going out)? }\end{array}$ & & & & \\
\hline
\end{tabular}


2 Overall, how satisfied ane you with the results of your Right hip fascial windowing?

\begin{tabular}{|c|c|c|c|}
\hline $\begin{array}{c}\text { Very } \\
\text { satisfied }\end{array}$ & $\begin{array}{c}\text { Somewhat } \\
\text { satisfied }^{2}\end{array}$ & $\begin{array}{c}\text { Somewhat } \\
\text { dissatisfied }^{3}\end{array}$ & $\begin{array}{c}\text { Very } \\
\text { dissatisfied }^{2}\end{array}$ \\
\hline
\end{tabular}

\section{Part 2: Pain}

Visual Analogue Pain Score

Please mark your current level of pain over the side of your Right hip. with a croses on the line balow:

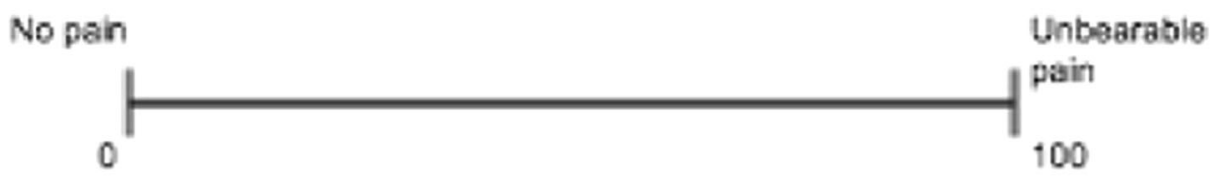

\section{Pain assessment}

Following your fascial windowing surgary, if you had any pain relief, approximately how long were you pain free betore your symptoms neturned?

(Please tick ( $($ ) ONE box)

\begin{tabular}{|l|l|}
\hline No relief at all & \\
\hline Less than 1 day & \\
\hline 1 week & \\
\hline 1 month & \\
\hline $2-3$ months & \\
\hline 6 months & \\
\hline 1 yoer & \\
\hline Over 1 year & \\
\hline I am still pain free & \\
\hline
\end{tabular}

\section{Lying on your side?}

Do you get pain lying on the affected side? (Please tick the relevant box).

\begin{tabular}{|c|c|}
\hline Yes & No \\
\hline & \\
\hline
\end{tabular}


Open Access This article is distributed under the terms of the Creative Commons Attribution 4.0 International License (http:// creativecommons.org/licenses/by/4.0/), which permits unrestricted use, distribution, and reproduction in any medium, provided you give appropriate credit to the original author(s) and the source, provide a link to the Creative Commons license, and indicate if changes were made.

\section{References}

1. Fearon AM, Scarvell JM, Neeman T, Cook JL, Cormick W, Smith PN (2013) Greater trochanteric pain syndrome: defining the clinical syndrome. Br J Sports Med 47(10):649-653. doi:10.1136/bjsports2012-091565

2. Fearon AM, Cook JL, Scarvell JM, Neeman T, Cormick W, Smith PN (2014) Greater trochanteric pain syndrome negatively affects work, physical activity and quality of life: a case control study. $\mathrm{J}$ Arthroplast 29(2):383-386. doi:10.1016/j.arth.2012.10.016

3. Klauser AS, Martinoli C, Tagliafico A, Bellmann-Weiler R, Feuchtner GM, Wick M, Jaschke WR (2013) Greater trochanteric pain syndrome. Semin Musculoskelet Radiol 17(1):43-48. doi:10. 1055/s-0033-1333913

4. Segal NA, Felson DT, Torner JC, Zhu Y, Curtis JR, Niu J, Nevitt MC (2007) Greater trochanteric pain syndrome: epidemiology and associated factors. Arch Phys Med Rehabil 88(8):988-992. doi:10. 1016/j.apmr.2007.04.014

5. Chowdhury R, Naaseri S, Lee J, Rajeswaran G (2014) Imaging and management of greater trochanteric pain syndrome. Postgrad Med J 90(1068):576-581. doi:10.1136/postgradmedj-2013-131828

6. Park KD, Lee WY, Lee J, Park MH, Ahn JK, Park Y (2016) Factors associated with the outcome of ultrasound-guided trochanteric Bursa injection in greater trochanteric pain syndrome: a retrospective cohort study. Pain Physician 19(4):E547-E557

7. Iorio R, Healy WL, Warren PD, Appleby D (2006) Lateral trochanteric pain following primary total hip arthroplasty. J Arthroplast 21(2):233-236. doi:10.1016/j.arth.2005.03.041

8. Sayed-Noor AS, Sjoden GO (2006) Greater trochanteric pain after total hip arthroplasty: the incidence, clinical outcome and associated factors. Hip Int 16(3):202-206

9. Farmer KW, Jones LC, Brownson KE, Khanuja HS, Hungerford MW (2010) Trochanteric bursitis after total hip arthroplasty: incidence and evaluation of response to treatment. J Arthroplast 25(2):208-212. doi:10.1016/j.arth.2009.02.008

10. Genth B, Von Düring M, Von Engelhardt LV, Ludwig J, Teske W, Von Schulze-Pellengahr C (2012) Analysis of the sensory innervations of the greater trochanter for improving the treatment of greater trochanteric pain syndrome. Clin Anat 25(8):1080-1086. doi:10. 1002/ca.22035

11. Collee G, Dijkmans BA, Vandenbroucke JP, Cats A (1991) Greater trochanteric pain syndrome (trochanteric bursitis) in low back pain. Scand J Rheumatol 20(4):262-266

12. Raman D, Haslock I (1982) Trochanteric bursitis-a frequent cause of 'hip' pain in rheumatoid arthritis. Ann Rheum Dis 41(6):602603

13. Reid D (2016) The management of greater trochanteric pain syndrome: a systematic literature review. J Orthop 13(1):15-28. doi:10. 1016/j.jor.2015.12.006

14. Baker RP, MacKeith SAC, Bannister GC (2005) Gluteal fascial transposition for trochanteric bursitis. Hip Int 15(4):212. doi:10. 5301/HIP.2008.1621

15. Drummond J, Fary C, Tran P (2016) The outcome of endoscopy for recalcitrant greater trochanteric pain syndrome. Arch Orthop Trauma Surg 136(11):1547-1554. doi:10.1007/ s00402-016-2511-z

16. Dawson J, Fitzpatrick R, Carr A, Murray D (1996) Questionnaire on the perceptions of patients about total hip replacement. Bone Joint J 78(2):185-190

17. Mahomed N, Gandhi R, Daltroy L, Katz JN (2011) The selfadministered patient satisfaction scale for primary hip and knee arthroplasty. Arthritis 2011:591253. doi:10.1155/2011/591253

18. Larose C, Guanche CA (2012) Paper 28: arthroscopic treatment of recalcitrant greater trochanteric bursitis with minimum two-year follow up. Arthroscopy 28(6, Suppl 2):e59-e60. doi:10.1016/j. arthro.2012.04.034

19. Voos JE, Shindle MK, Pruett A, Asnis PD, Kelly BT (2009) Endoscopic repair of gluteus Medius tendon tears of the hip. Am J Sports Med 37(4):743-747. doi:10.1177/0363546508328412

20. Walsh MJ, Walton JR, Walsh NA (2011) Surgical repair of the gluteal tendons: a report of 72 cases. J Arthroplast 26(8):1514 1519. doi:10.1016/j.arth.2011.03.004

21. Baker CL Jr, Massie RV, Hurt WG, Savory CG (2007) Arthroscopic bursectomy for recalcitrant trochanteric bursitis. Arthroscopy 23(8): 827-832. doi:10.1016/j.arthro.2007.02.015 